\section{The Nano Age?}

Simon Sze famously announced that the end of the Iron Age and the beginning of the Silicon Age was in 1968, when the scientific community published more papers on silicon than on steel. In 2004, papers on nano outran publications on silicon by 2:1. Have we taken leave of the Silicon Age already? Or have we taken leave of our senses?

As scientists, we generally tend to work on topics that we think will have a high impact on scientific progress. For materials researchers, this means that there is usually a strong correlation between the number of papers and economic activity. For a few representative materials, Table I shows how 2004 publications in a given area track the size of that industry (worldwide revenue in billions of dollars per year). Interestingly, the correlation to 2004 revenues is pretty weak, but the correlation to projected future revenues (2010) is much closer. Our scientific activity appears to focus on the problems we guess will be important in the future (further exemplified by the $\$ 1$ million Dan David Prize, which recognizes the impact of the materials science field on the future of society; see Research/Researchers in this issue).

By any measure, "nano" stands out as an unusual topic in materials science.

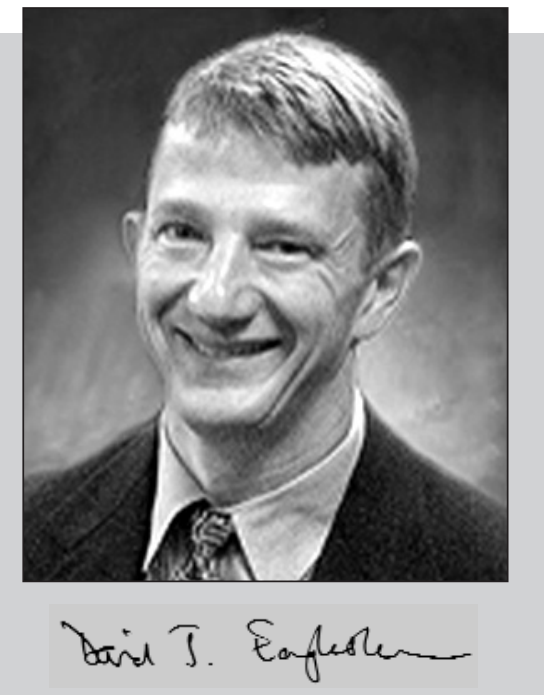

Figure 1 shows a graph of the annual publications (by title) in a variety of topics over the last few decades. Publications with "nano" in the title ran at about 500/year (references to wavelength only), then took off in 1991, shot past silicon in 2000, and doubled those on silicon today, with no sign that the exponential rate is ending.

This suggests the end of the Silicon Age and the start of the Nano Age in

\begin{tabular}{|c|c|c|c|c|c|c|}
\hline \multicolumn{7}{|c|}{ Table I: Correlation of Publications to Economic Activity. } \\
\hline Topic & $\begin{array}{c}2004 \\
\text { Papers }\end{array}$ & $\begin{array}{c}2004 \\
\text { Revenue } \\
\text { (\$ Billions) }\end{array}$ & $\begin{array}{c}2004 \\
\text { Ratio } \\
\text { (paper/\$1B revenue) }\end{array}$ & Growth & $\begin{array}{c}2010 \\
\text { Revenue } \\
\text { (\$ Billions) }\end{array}$ & $\begin{array}{c}2010 \\
\text { Ratio } \\
\text { (paper/\$1B revenue) }\end{array}$ \\
\hline Silicon & 14,185 & 160 & 88.7 & $10 \%$ & 290 & 49 \\
\hline III-V & 1300 & 13 & 100.0 & $17 \%$ & 33 & 39 \\
\hline Steel & 5354 & 205 & 26.1 & $3 \%$ & 245 & 22 \\
\hline Nitrides & 1200 & 2.5 & 480.0 & $47 \%$ & 25 & 48 \\
\hline Nano & 30,828 & $?$ & $?$ & $?$ & $?$ & $?$ \\
\hline
\end{tabular}

2000. But when Sze proclaimed the Silicon Age, there was already a very substantial industry in the field. Silicon was infiltrating every imaginable device and radically changing whole areas of human existence. The transistor radio had redefined entertainment, and compact computation had enabled us to reach the moon. Revenues were only $\sim$ \$10 billion worldwide, but they were booming, and the writing was already on the wall for the next tenfold increase in growth. Is nano anywhere near?

Popular articles on nanotechnology typically point out that there are current nanotechnology products as well as future promise. These products include sunscreens and stain-resistant pants, tennis balls, and ski waxes. This list, while it hints at an extraordinary breadth of capabilities, does not instantly suggest a worldwide industry that dwarfs the semiconductor and steel industries.

However, nano is not just a single material, class of material, or processing technique. It is rightly criticized as a catch-all term that includes most materials science. The official U.S. National Nanotechnology Initiative (NNI) definition is "the control of materials at the sub-100-nm level." In this broadest sense, then, nanotechnology captures a very wide thrust in the materials community. There is a widespread excitement that the emerging capabilities now allow us to control materials at the nanolevel-not just in the laboratory but on a manufacturable scale. In this light, the breathless hype can be assessed in a more measured way.

So is nanotechnology poised to grow into an industry larger than semiconductor electronics? In one sense, it already has.

The NNI's assessment of nanotechnology's
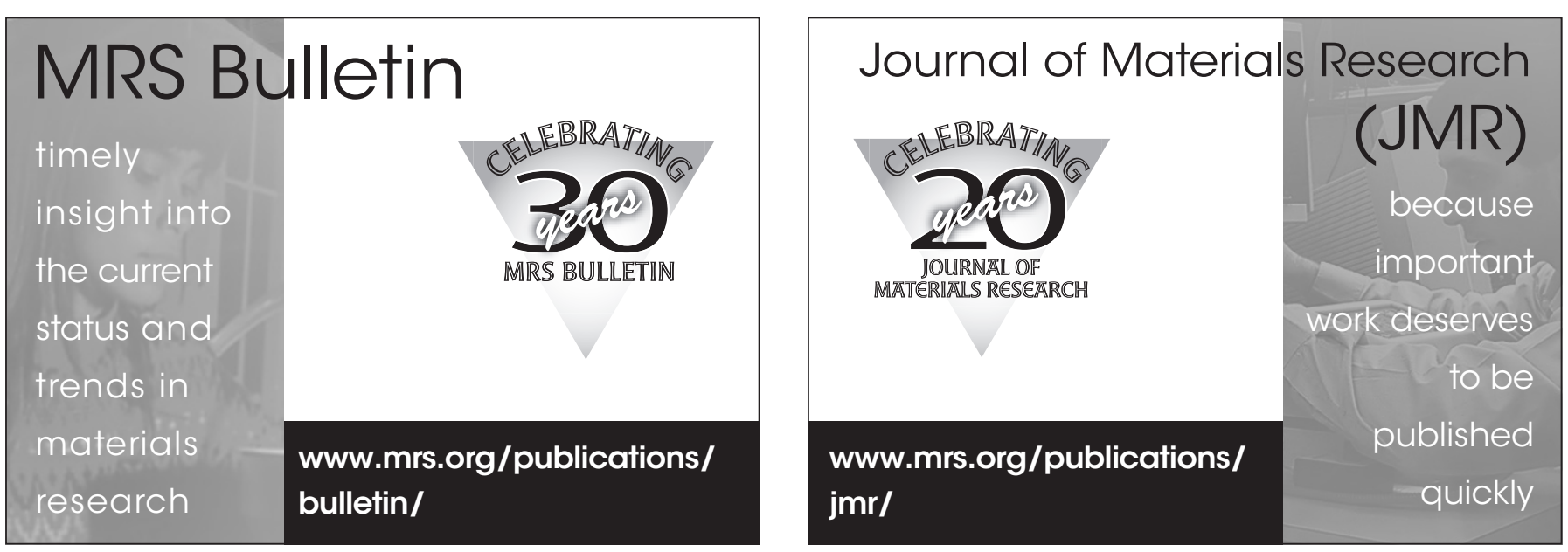


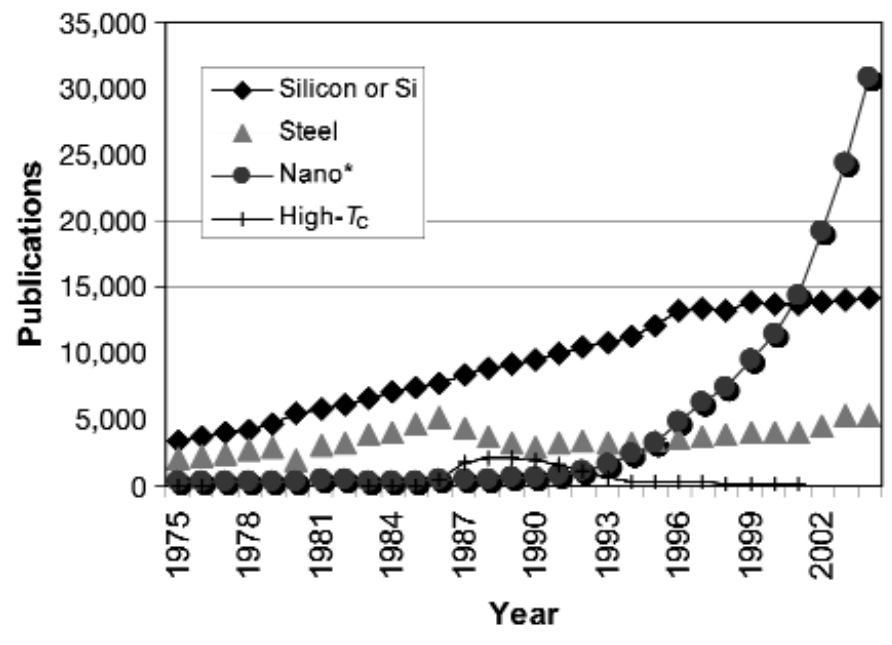

Figure 1. Publications over time by material topic.

\section{Resources (accessed March 2005)}

Nanotech applications:

www.usatoday.com/tech/news/techinnovations/ 200307-23-robopants_x.htm

\section{Revenuelgrowth estimates:}

Silicon: www.sia-online.org/pre_release.cfm?ID=321

Nitrides: www.compoundsemiconductor.net/articles/ magazine/9/12/2/1

Steel: home.aigonline.com/content/ 0,1109,18028-847-ceo,00.html

GaAs: www.bccresearch.com/editors/RGB-196R.html Note: This is a "compound semiconductor" number and is far higher than GaAs chips alone ( $\$ 2.7$ billion growing at $15 \%$ ) see: www.compoundsemiconductor.net/articles/ magazine $/ 9 / 5 / 1 / 1$. potential includes two very large existing industries. Catalytic materials have been nanostructured for at least a century, and this industry ( $\$ 100$ billion) is included in the NNI's notorious estimate of a future trillion-dollar nanotechnology economy. The electronics industry, on the other hand, represents a wholly new class of nanomanufacturing capability. In 2001, as the microelectronics industry moved below the $100 \mathrm{~nm}$ feature size, the entire industry ( $\$ 300$ billion of the NNI's trilliondollar projection) dropped into the nanotechnology category. This evolution of semiconductor technology represents a true revolution in our capability to manipulate materials at the nanoscale in mass manufacturing. The semiconductor industry is not only capable of "top-down" manufacturing at extraordinary scales, but now also increasingly adopts manufacturing technologies with a "bottom-up" flavor, such as self-limiting atomic layer deposition techniques and self-assembled monolayers, as well as the use of nanoanalytical tools (such as atomic force microscopy) in manufacturing. One promise of the nanotechnology field is that now that we have made electronics into nanoelectronics, we can apply similar techniques to other fields.

In addition to catalysts and electronics, the NNI's trillion-dollar projection includes half of the $\$ 180$ billion pharmaceuticals industry, and a category of "nanostructured materials and processes" that is estimated at $\$ 340$ billion. In addition to "nanopants," this catch-all category spans many of the myriad applications of nanotechnology that can be seen at MRS meetings: displays, batteries, hydrogen storage, photovoltaics, photochemical converters, and water separation. Each of these arenas is a huge global industry in its own right. Laboratory results that are already on display at research meetings like MRS suggest that "nanotechnology" materials engineering capabilities can successfully be applied in these segments.

So, hype or reality? The Nano Age seems to represent for materials researchers a new confidence that we can apply our control of materials to revolutionize the materials economy. "Nano" is the term that has captured and now encapsulates this sense of possibility. The current "nano" industry, by NNI's measure, is more than $\$ 280$ billion, giving a respectable paper/revenue ratio of $\sim 100$ for 2004. This nano "industry" would need to grow at about $15 \%$ to put the projected paper/revenue ratio in 2010 below 48. If nanotechnology applications in healthcare, energy, and processing deliver on their promises, then we will indeed be in the Nano Age.

DAVID J. EAGLESHAM 2005 MRS President President@mrs.org

\section{Missing Important Issues of MRS Bulletin?} Back Issues are still available!

Contact MRS for details-

\section{MRS}

506 Keystone Drive

Warrendale, PA 15086-7573 U.S.A.

Tel: $\quad 724-779-3003$

Fax: $724-779-8313$

E-mail: info@mrs.org

www.mrs.org/publications/

\section{MRS Bulletin Back Issues}

Order by Volume and Issue Number. $\$ 30.00$ per issue.

\section{VOLUME $29 \cdot 2004$}

No. 1 Toward Applications of Ceramic Nanostructures

No. 2 New Developments in Colloid Science

No. 3 High-Resolution Three-Dimensional X-Ray Microscopy

No. 4 Advances in Carbon Nanotubes

No. 5 Construction Materials-From Innovation to Conservation

No. 6 Molecular Transport Junctions

No. 7 Scanning Probe Microscopy in Materials Science

No. 8 High-Performance YBCO-Coated Superconductor Wires

No. 9 Single-Article Issue: Pursuit of the Small; Nanoscale Surface Mass Transport; Self-Assembly; Exchange-Biased Nanostructures; Electronics for National Security

No. 10 Novel Materials and Applications of Electronic Noses and Tongues

No. 11 Emerging Solid-State Memory Technologies

No. 12 Solid-Liquid Interfaces-Molecular Structure, Thermodynamics and Crystallization 